\title{
Observation of thermally etched grain boundaries with the
}

\section{FIB/TEM technique}

Y. Palizdar', D. San Martin², M Ward', R. C. Cochrane³, R. Brydson ${ }^{3}$, and A. J. $\mathrm{Scott}^{3}$

${ }^{1}$ Nanotechnology and advanced materials department, Materials and energy research centre (MERC), Karaj, Iran

${ }^{2}$ MATERALIA group, Department of Physical Metallurgy, (CENIM-CSIC), Centro Nacional de Investigaciones Metalúrgicas Av. Gregorio del Amo 8, 20040 Madrid, Spain

${ }^{3}$ Institute for Materials Research, SPEME, University of Leeds, Leeds LS2 9JT UK

Tel: (+98 21) 88771626-7

Fax: (+98 21) 88773352

Emails: y.palizdar@merc.ac.ir;

Abstract: Thermal etching is a method which is able to reveal and characterize grain boundaries, twins or dislocation structures and determine parameters such as grain boundary energies, surface diffusivities or study phase transformations in steels, intermetallics or ceramic materials. This method relies on the preferential transfer of matter away from grain boundaries on a polished sample during heating at high temperatures in an inert/vacuum atmosphere. The evaporation/diffusion of atoms at 
high temperatures results in the formation of grooves at the intersections of the planes of grain/twin boundaries with the polished surface. This work describes how the combined use of Focussed Ion Beam and Transmission Electron Microscopy can be used to characterize not only the grooves and their profile with the surface, but also the grain boundary line below the groove, this method being complementary to the commonly used scanning probe techniques.

Keywords: Steel, Thermal etching, Focussed Ion Beam, Transmission Electron Microscopy.

Materials Characterization 84 (2013) 28-33

http://dx.doi.org/10.1016/j.matchar.2013.07.003 


\section{Introduction}

When a finely pre-polished surface of a metal is heat treated to high temperatures under high vacuum conditions, grooves will be formed, revealing crystal boundaries/imperfections in a similar way to chemical etching procedures. During heating, at the intersection of a grain boundary (GB) plane with the polished surface, local equilibrium is established between the surface tension at the free surface and the GB [1]. Equilibrium is set-up rapidly and preferential atom diffusion/evaporation takes place. The free surface adjacent to the line, where the grain/twin boundary emerges, becomes tightly curved, forming so-called thermal grooves. These grooves are visible under a light optical microscope [2]. This method, known as thermal etching or thermal grooving, has been used in steels and other metals in order to investigate grain boundaries, stacking faults, twins or dislocation structures, providing important information regarding the surface, GB energies or surface self-diffusivity [3-10]. This method has also been employed in ceramic or intermetallic materials for similar purposes [11-13].

The generation of thermal grooving has attracted much attention recently for characterization, in-situ or ex-situ, of processes such as grain growth or solid-solid phase transformations [14-20]. Among different etching techniques, thermal etching has been demonstrated as a reliable method to reveal grain boundaries since prominent grooves originate at those locations where grain boundaries intersect with the pre-polished surface. It has been argued that thermal grooves can develop in association with both mobile and stationary grain boundaries. It is generally accepted that surface grooves that are formed where the grain boundaries are stationary are an exact copy of the grain structure existing in the bulk of the sample. However, there 
has been some debate regarding the pinning effects of mobile grain boundaries and whether such grooves affect their mobility [14,21-24].

Recently, thermal etching has been the subject of a number of experimental studies in metals/intermetallics in which atomic force microscopy or scanning probe microscopy has been utilised to characterize thermal grooves [7, 23-26]. With these techniques it is possible to measure the groove topography and dihedral angle at the root of the groove with high accuracy. However, information from these microscopy techniques is limited to the surface. To the authors' knowledge there has been limited work concerning the experimental characterization of the structure below the thermally formed grooves which would provide valuable information regarding pinning effects as well as GB mobility and would help to validate/corroborate existing models. Current technological developments in microscopy enable us to carry out detailed characterization not only concerning the groove profile but also the region of material underneath of the groove. With the aid of Focussed Ion Beam and Transmission Electron Microscopy techniques the authors show that it is possible to prepare a cross-sectional sample of a section of thermally etched prior austenite grain boundaries (PAGBs) that can provide useful additional information on thermal grooving processes and grain growth dynamics.

\section{Materials and experimental methods}

A low-carbon aluminium-alloyed steel has been employed for this investigation. The composition of this steel is given in Table 1. More details about the steel production and microstructure can be found elsewhere [27]. In order to reveal the PAGBs by thermal etching, cylindrical samples were first mounted in bakelite. Subsequently, for each sample, a surface of 2-3 mm in width was polished parallel to the main axis of 
the cylinder using standard metallographic techniques and finishing with 1- $\mu$ m diamond cloth. The specimens were then carefully removed from the bakelite avoiding damage to the polished surfaces. The heat treatments were carried out in a Bahr 805D high resolution dilatometer under high vacuum conditions $\left(10^{-5} \mathrm{mbar}\right)$ to avoid oxide formation on the polished surfaces. The specimens were heated following a multi-step cycle: 1) heating rate of $14^{\circ} \mathrm{C} / \mathrm{s}$ up to $650{ }^{\circ} \mathrm{C}$; 2) heating rate of $6.6^{\circ} \mathrm{C} / \mathrm{s}$ up to $900{ }^{\circ} \mathrm{C}$; and 3) heating rate of $2{ }^{\circ} \mathrm{C} / \mathrm{s}$ up to the final austenitization temperatures $\left(1150{ }^{\circ} \mathrm{C}\right.$ and $1250{ }^{\circ} \mathrm{C}$ respectively) and held for $600 \mathrm{~s}$. The samples were quenched immediately after the austenitization heat treatment at an average cooling rate of 295 ${ }^{\circ} \mathrm{C} / \mathrm{s}$. Figure 1 shows the heating/cooling cycle as recorded by the dilatometer. To check the as-quenched microstructure, an additional dilatometry sample was heat treated according to Figure 1, cut in half, mounted in bakelite, polished using standard metallographic techniques and etched with Nital-2\% for inspection using a Nikon Epiphot 200 light microscope. Cross-sections of thermally etched grain boundaries (austenetised at $1150{ }^{\circ} \mathrm{C}$ ) were prepared using a FEI NOVA200 dual beam FIB/SEM (Focussed Ion Beam/ Scanning Electron Microscope). A $30 \mathrm{keV} \mathrm{Ga} \mathrm{ion} \mathrm{beam} \mathrm{was}$ used, and for final thinning the beam current was varied from 500 to 50 pA. An FEI CM200 TEM (Transmission Electron Microscope) was employed to examine the FIB sections. In addition, a thermally etched sample (austenetised at $1250{ }^{\circ} \mathrm{C}$ ) was investigated using the same light microscopy method described above.

\section{Results}

Figure 2 shows an optical micrograph of the thermally etched microstructure. Nomarski microscopy has been used to highlight microtopographic surface features 
which aids the visualization of the PAGBs produced at $1150{ }^{\circ} \mathrm{C}$. Figures $3 \mathrm{~A}$ and $3 \mathrm{~B}$ illustrate two SEM images of the selected areas (areas A and B) from where sectioning of thin samples has been carried out by using the focussed ion beam technique. TEM micrographs of each FIB section have been taken at different magnifications (see Figures 4 (region A) and 5 (region B). In these TEM images the GB line, below the sample surface, and also the free surface have been indicated. Figures 4(B) and 5(B) also show a schematic representation of each groove and GB line beneath the groove derived from the TEM images. The angle between the GB line and the surface normal has been estimated. The depth of the groove has also been quantified from these images. A light microscope image of a thermally etched sample at $1250{ }^{\circ} \mathrm{C}$ is shown in Figure 6.

\section{Discussion}

After the austenitisation heat treatment at $1150^{\circ} \mathrm{C}$ the sample has been quenched reaching an average cooling rate of $295^{\circ} \mathrm{C} / \mathrm{s}$ (Figure 1). At this rate it is quite unlikely that any grooves may have formed during cooling. Therefore, it could be assumed that grooves formed on the polished surface represent former locations of prior austenite grain boundaries at $1150{ }^{\circ} \mathrm{C}$. Figure 7 shows the temperature evolution of the relative change in length experienced by the sample during the heating/cooling treatment (an insert has been included in Figure 7 to show, with more detail, the start and end temperatures of the dilatation observed during cooling). A clear dilation is observed between $650{ }^{\circ} \mathrm{C}$ and $425^{\circ} \mathrm{C}$. Figure 8 shows an optical micrograph of the as-quenched microstructure. The border of the sample has been delineated using a white dashed line. From this micrograph it can be concluded that the microstructure is a combination of bainite and martensite. To support these experimental observations, 
the critical transformation temperatures Bs and Ms, that correspond to the start of the bainitic and martensitic reactions as a function of composition respectively, have been calculated using the program MUCG83 developed by Bhadeshia and collaborators [28] . The program is based on a model that takes into account all the alloying elements included in the composition of the steel under investigation in this work (Table 1). According to this model, for our steel, Bs $=674{ }^{\circ} \mathrm{C}$ and $\mathrm{Ms}=526{ }^{\circ} \mathrm{C}$. The Bs calculated shows very good agreement with the value estimated from experimental dilatometry plot (Figure $7, \mathrm{Bs}=650{ }^{\circ} \mathrm{C}$ ). Thus it could be argued that the start temperature of the dilatation observed in Figure 7 represents the start of the bainitic transformation. In addition, as the Ms temperature lies above $425{ }^{\circ} \mathrm{C}$ (finishing transformation temperature experimentally estimated in Figure 7), it should be expected that some martensite is present in the microstructure along with bainite. Since bainite and martensite do not affect the prior austenite grain boundaries, it can be deduced that austenite grain boundaries are likely to remain unchanged. Therefore, based on these calculations and experimental observations it can be concluded that grain boundary lines observed below the grooves in Figures 4 and 5 are likely to be prior austenite grain boundaries.

It has been extensively discussed in the scientific literature that thermal grooves can develop in association with mobile as well as stationary grain boundaries [1,3, 21-23]. Mullins [21, 22] and Allen [3] showed that moving grooves have a different profile to their stationary counterparts. Figure 9 shows a schematic of a characteristic steady-state profile of a thermal groove formed at a migrating GB at a constant speed [21]. A stationary GB would appear perpendicular to the specimen surface $(\theta \approx 0)$ while moving grooves would form a certain angle $(\theta \neq 0)$ with the surface normal. Figure 9 is very similar to GB profiles shown in Figures 4 and 5, 
which allows us to suggest that the GBs investigated describe moving grooves rather than stationary ones.

The work of Rabkin and co-workers highlights the diversity of GB grooves observed in Ni and NiAl materials [1,23,24]. Based on the work of Mullins [21,22], these authors predicted asymmetric groove profiles similar to the one shown in Figure 4, by accounting in their model for GB grooving with simultaneous GB sliding, and considering that only surface diffusion is responsible for the observed grooves (which is true if the groove width is lower than $10 \mu \mathrm{m}[5])$.

In his seminal work on mobile grain boundaries, Mullins [21, 22] suggested that under certain conditions thermal grooves could pin grain boundaries at the surface. He presented experimental evidence of spasmodic/jerky GB migration, in which the GBs were sequentially pinned and unpinned at the surface, leaving a series of parallel (ghost) grooves. He adapted his theory for stationary GBs to mobile ones and demonstrated that a grain boundary would become stuck at the surface if the magnitude of the angle $\theta$ (see Figure 9) with the surface normal was less than a critical value " $\theta_{c}$ “. Under these conditions, he concluded that thermal grooves would be decelerated and become temporarily trapped, behaviour that would explain the spasmodic migration he observed. These ghost grooves have not been observed in the thermally etched microstructure of the investigated steel after heating to $1150{ }^{\circ} \mathrm{C}$ (Figure 2). However, they have been clearly observed after heating to $1250{ }^{\circ} \mathrm{C}$ (see Figure 6). Allen [3] suggested that spasmodic movements considered by Mullins were a special case only applicable at slow grain growth rates. Support for the work of Allen can be found in the work of Halliday [20]. Similarly, in a detailed investigation concerned with the study of grain growth in different microalloyed steels, Garcia de Andrés and co-workers observed that the higher the austenitization temperature, the 
more pronounced were the ghost grooves/traces in the microstructure [14]. Furthermore, for the same heating temperature, longer times would also favour the occurrence of ghost traces. These authors related the decrease in GB mobility to the manifestation of GB ghost traces. The higher the austenite grain size, the lower its mobility and the greater the interference of the grooves with the GB movement on the surface. In addition, at higher temperatures, surface diffusion would be more prominent, leading to deeper grooves that would hinder the advance of the GB. These observations concerning ghost groove formation conditions seem to agree well with experimental observations exposed in this work: 1) at lower heating temperatures, grains are still small (Figure 2; average grain size $=37 \mu \mathrm{m}$ ), their mobility is expected to be high, pinning by grooves is improbable and ghost traces are not likely to be observed; and 2) the angle between the GB and the surface normal has been found to be quite large for the two cases investigated (23 and $30^{\circ}$ ), which could suggest that these angles are above the critical angle, $\theta_{c}$, below which Mullins postulated that pinning would take place (and ghost traces would be observed). At the higher temperature (1250 ${ }^{\circ} \mathrm{C}$, Figure 6$)$, where we have a much greater average grain size (181 $\mu \mathrm{m})$ GB migration is much slower, pinning is expected to happen and ghost traces are present in the microstructure.

\section{Conclusion:}

Thermally etched austenite boundaries have been investigated by FIB/TEM technique. The authors show that with FIB is possible to prepared sample crosssections of thermally etched PAGBs and provide images for the investigation of the whole system "groove/GB line” that can supply very useful additional information on thermal grooving processes and grain growth dynamics. The combined use of these 
techniques is an excellent complementary method to AFM or SPM which are extensively used to characterize thermally etched grain boundaries.

\section{References:}

[1] Rabkin E, Klinger L. The fascination of grain boundary grooves. Mater Sci Technol 2001;17:772-6.

[2] San Martín D, Palizdar Y, Cochrane RC, Brydson R, Scott AJ. Application of Nomarski differential interference contrast microscopy to highlight the prior austenite grain boundaries revealed by thermal etching. Mater Charact 2010;61:584-8.

[3] Allen DJ. Thermal Grooving at migrating grain boundaries. Scripta Metall 1982;16:5-9.

[4] Doeser BA, Thomas SW, Moon JR. Thermal etching of copper. Acta Metall 1976;24:773-8.

[5] Hondros ED, Moore AJW. Evaporation and Thermal Etching. Acta Metall 1960;8:647-53.

[6] Mullins WW, Shewmon PG. The Kinetics of Grain Boundary Grooving in Copper. Acta Metall 1959;7:163-70.

[7] Amouyal Y, Rabkin E. A scanning force microscopy study of grain boundary energy in copper subjected to equal channel angular pressing. Acta Mater 2007;55:6681-9.

[8] Ling FW, Starke Jr EA. Thermal Etching of $\beta$ Ti-V Alloys. Metallography 1972:5:399-07.

[9] Zhao B, Verhasselt JCh, Shvindlerman LS, Gottstein G. Measurement of grain boundary triple line energy in copper. Acta Mater 2010;58:5646-53. 
[10] Jin MX, Shimada E, Ikuma Y. Grain boundary grooving by surface diffusion in SrTiO3 bicrystal. J Mater Res 1999;14:2548-53.

[11] van der Berg NG, Malherbe JB, Botha AJ, Friedland E. Thermal etching of SiC. Appl Surf Sci 2012;258: 5561-6

[12] Amouyal Y, Rabkin R, Mishin Y. Correlation between grain boundary energy and geometry in Ni-rich NiAl. Acta Mater 2005;53:3795-05.

[13] Munoz NE, Gilliss SR, Carter CB. Remnant grooves on alumina surfaces. Surf Sci 2004;573:391-02.

[14] García de Andres C, Caballero FG, Capdevila C, San Martin D. Revealing austenite grain boundaries by thermal etching: advantages and disadvantages. Mater Charact 2002;49:121-7.

[15] Garcia de Andres C, Bartolome MJ, Capdevila C, San Martin D, Caballero FG, Lopez V. Metallographic techniques for the determination of the austenite grain size in medium-carbon microalloyed steels. Mater Charact 2001;46:389-98.

[16] Yin H, Emi T, Shibata H. Morphological Instability $\delta$-ferrite $/ \gamma$-austenite Interphase Boundary in Low Carbon Steels. Acta Mater. 1999;47:1523-35.

[17] Dippenaar RJ, Phelan DJ. Delta-Ferrite Recovery Structures in Low-Carbon Steels. Metall Mater Trans B 2003;34:495-01.

[18] Phelan D, Dippenaar R. Widmanstätten Ferrite Plate Formation in Low-Carbon Steels. Metall Mater Trans A 2004;35:3702-6.

[19] Schmidt E, Wang Y, Sridhar S. A Study of Non-isothermal Austenite Formation and Decomposition in Fe-C-Mn Alloys. Metall Mater Trans A 2006;37:1799-10.

[20] Halliday WI. Determination of the austenitic grain size of steel using a thermal etching method. ISI Special Report No 81. London: Iron and Steel Institute; 1963, p. $65-7$. 
[21] Mullins WW. Theory of thermal grooving. J Appl Phys 1957;28:333-9.

[22] Mullins WW. The effect of thermal grooving on grain boundary motion. Acta Metall 1958;6:414-27.

[23] Rabkin E, Klinger L, Izyumova T, Berner A, Semenov V. Grain boundary grooving with simultaneous grain boundary sliding in Ni-rich NiAl. Acta Mater 2001; 49:1429-38.

[24] Rabkin E, Amouyal Y, Klinger L. Scanning probe microscopy study of grain boundary migration in NiAl. Acta Mater 2004;52:4953-9.

[25] Schöllhammer J, Chang L-S, Rabkin E, Baretzky B, Gust W, Mittemeijer EJ. Measurement of the profile and the dihedral angle of grain boundary grooves by atomic force microscopy. Z Metallkde 1999;90:687-90.

[26] Zhang W, Sachenko P, Gladwell I. Thermal grain boundary grooving with anisotropic surface free energies. Acta Mater 2004;52:107-16.

[27] Palizdar Y, Cochrane RC, Brydson R, Crowther D, San Martin D, Scott AJ. The effect of deliberate aluminium additions on the microstructure of rolled steel plate characterized using EBSD. Mater Charact 2010;61:159-67.

[28] Link to Materials Algorithms Project Program Library of the University of Cambridge: http://www.msm.cam.ac.uk/map/steel/programs/mucg83.html. 
Figure Captions

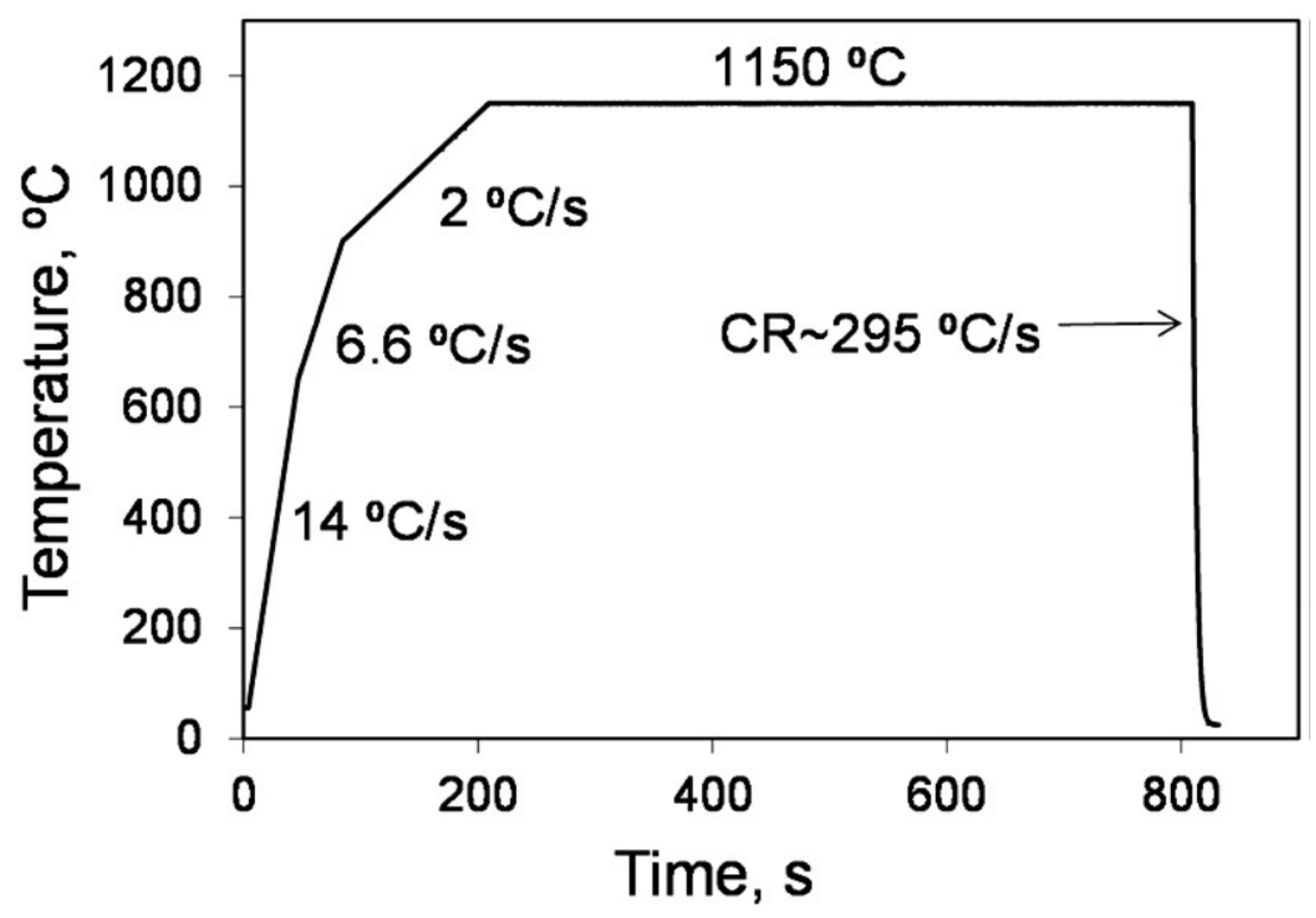

Figure 1 Heating/cooling cycle applied to the sample as recorded by the dilatometer 


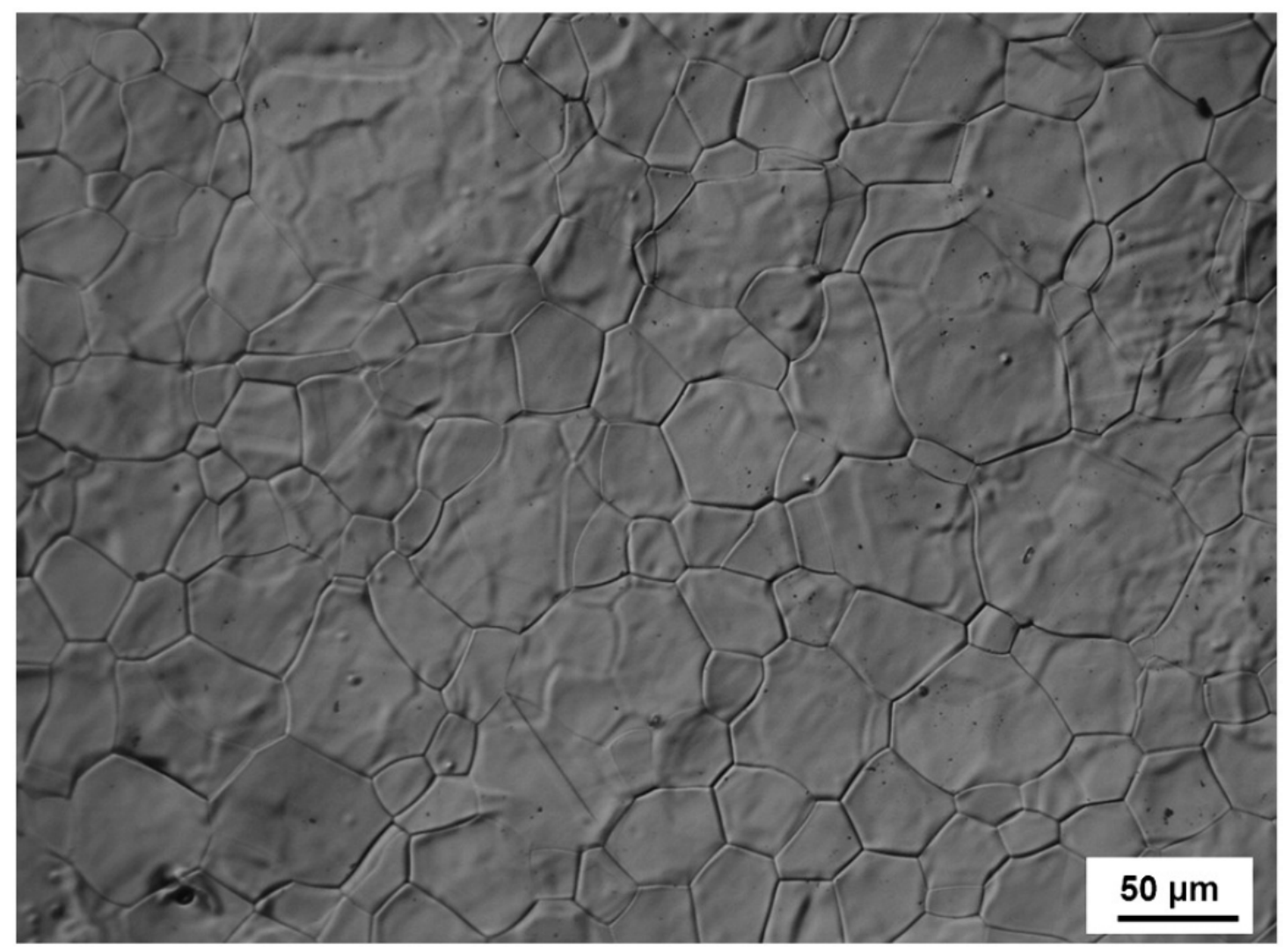

Figure 2 Light optical micrograph of the prior austenite microstructure of a low carbon steel at $1150{ }^{\circ} \mathrm{C}$ revealed by thermal etching. Nomarsky microscopy has been employed to highlight the microtopographic features such as thermal grooves at Ferrite Grain Boundaries (FGB) and Prior Austenite Grain Boundaries (PAGB). 

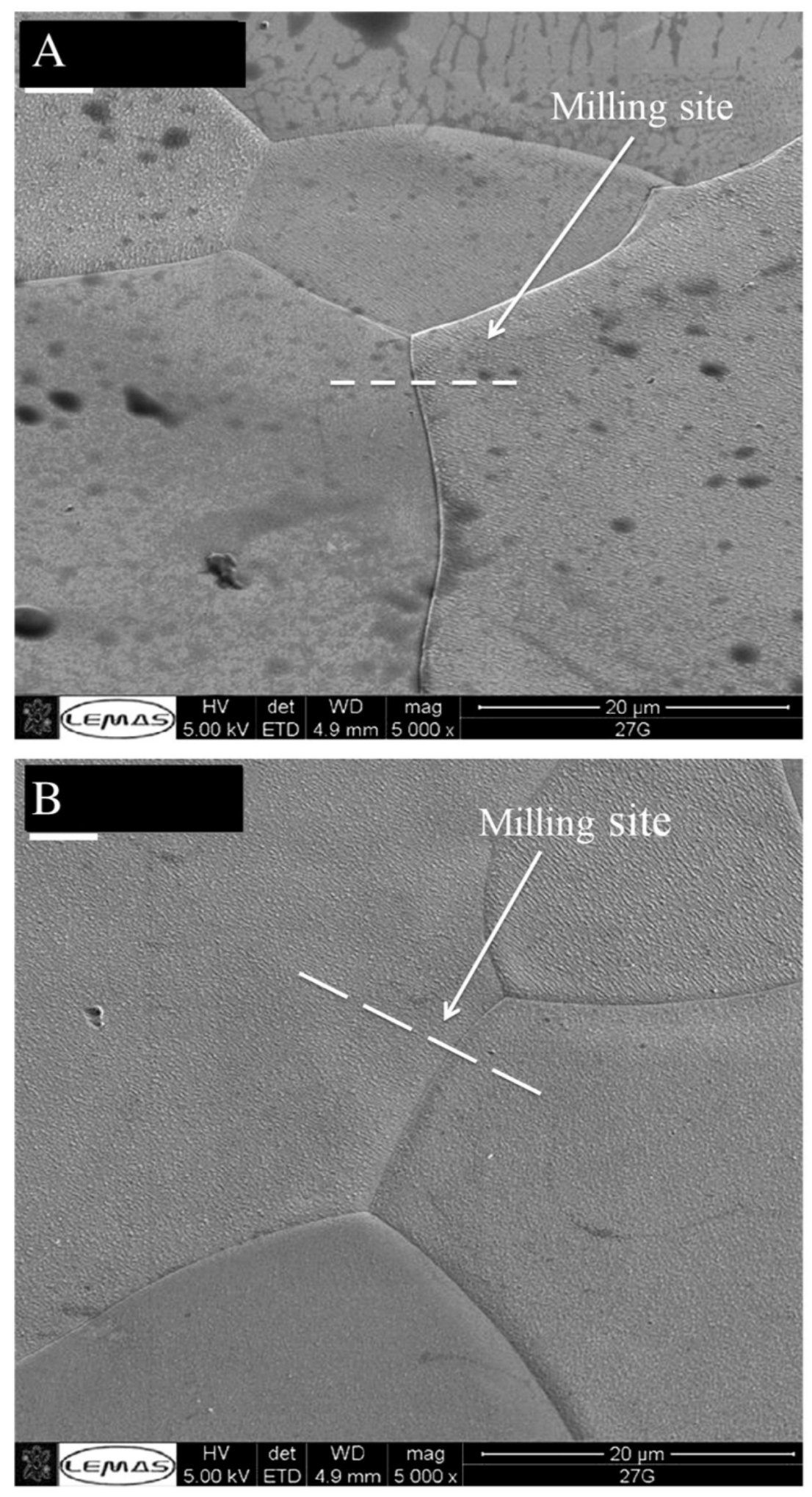

Figure 3 SEM images of the two representative areas from where the FIB sections have been obtained in the thermally etched sample (figure 1). 

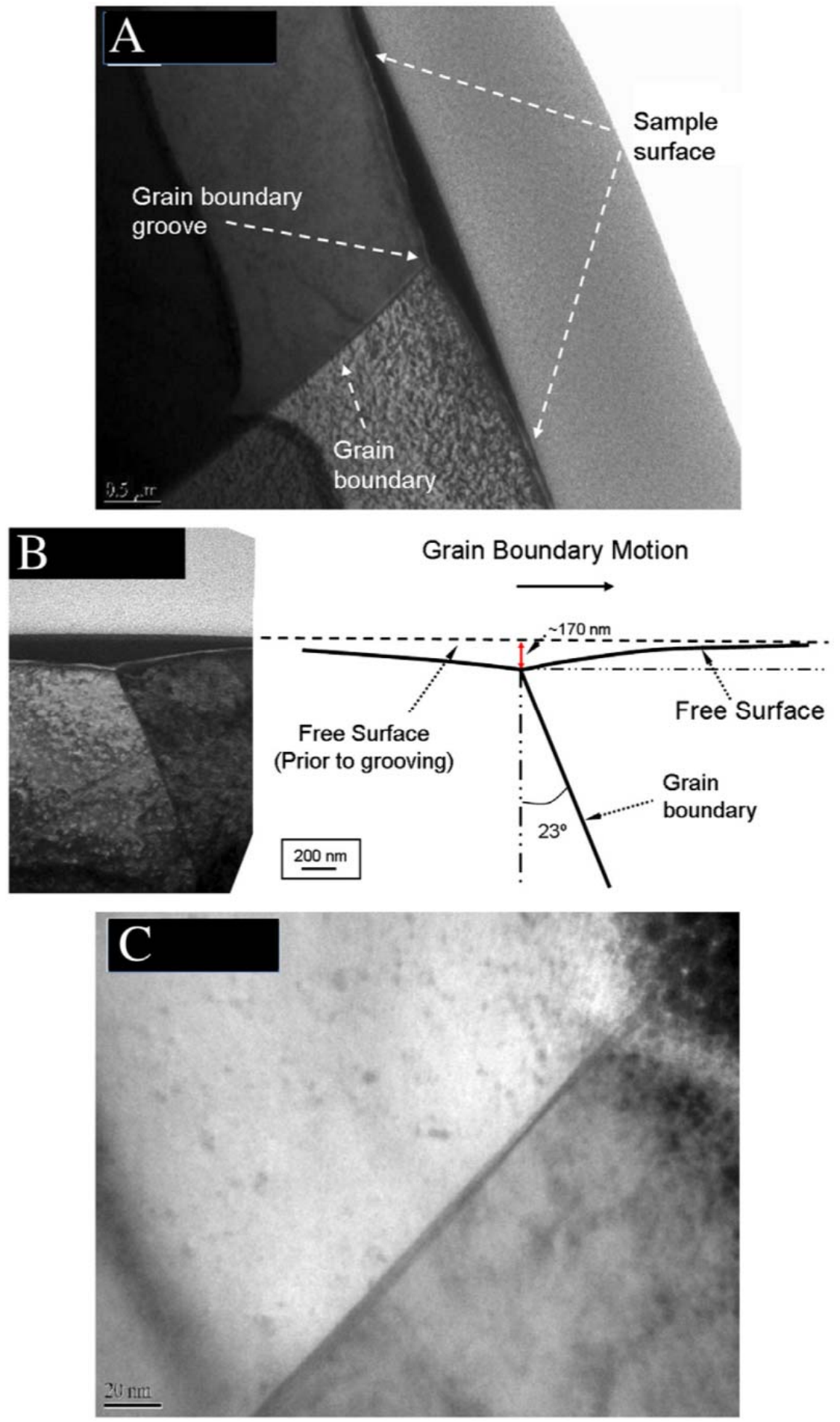

Figure 4 A), C) TEM micrographs taken at different magnifications showing a thermally etched grain boundary obtained by FIB sectioning from an area shown in Figure 2A; B) schematic of the groove and grain boundary line beneath the groove as shown in TEM image. 


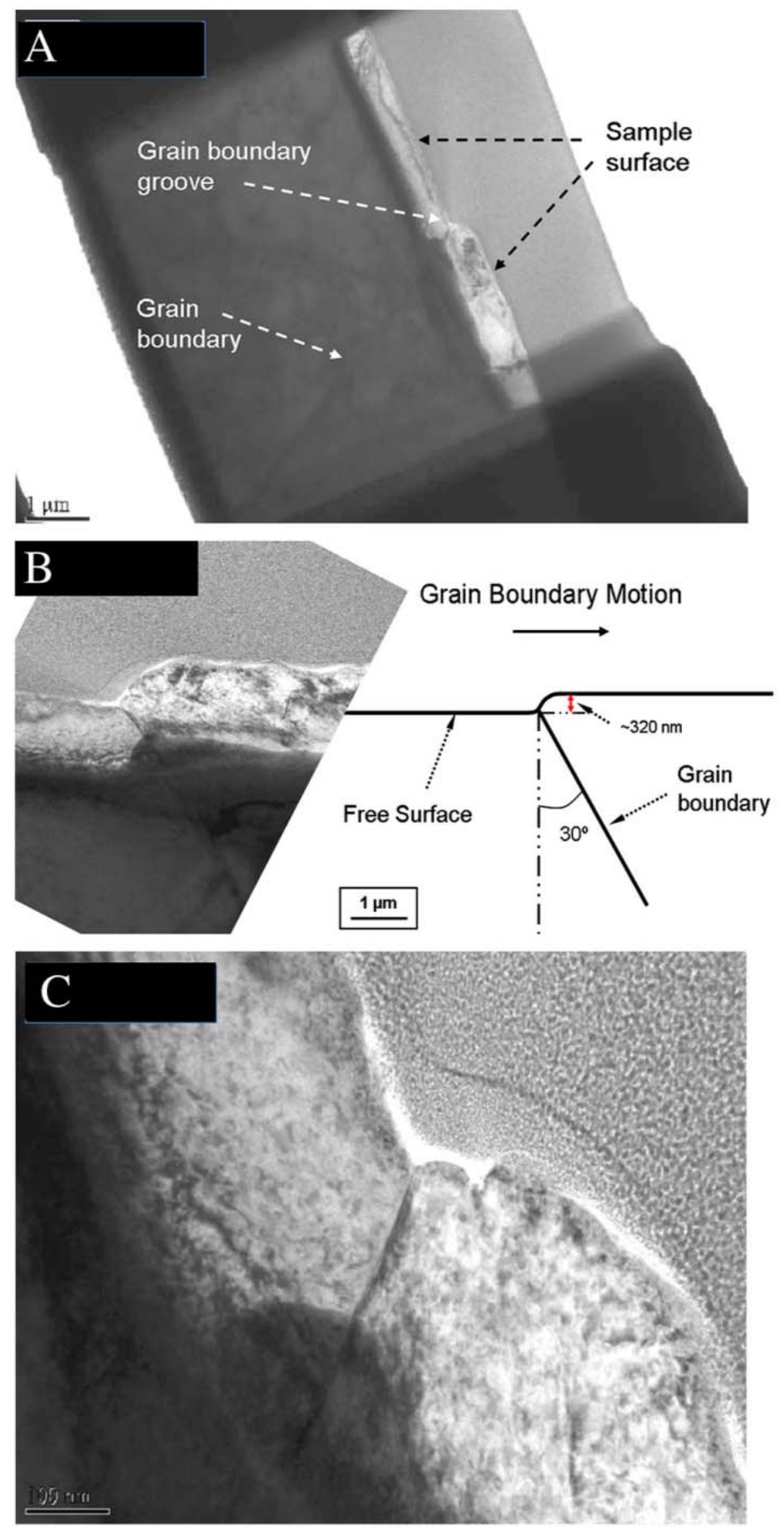

Figure 5 A), C), TEM micrographs taken at different magnifications showing a thermally etched grain boundary obtained by FIB sectioning from an area shown in Figure 2B; B) schematic of the groove and grain boundary line beneath the groove as shown in TEM image . 


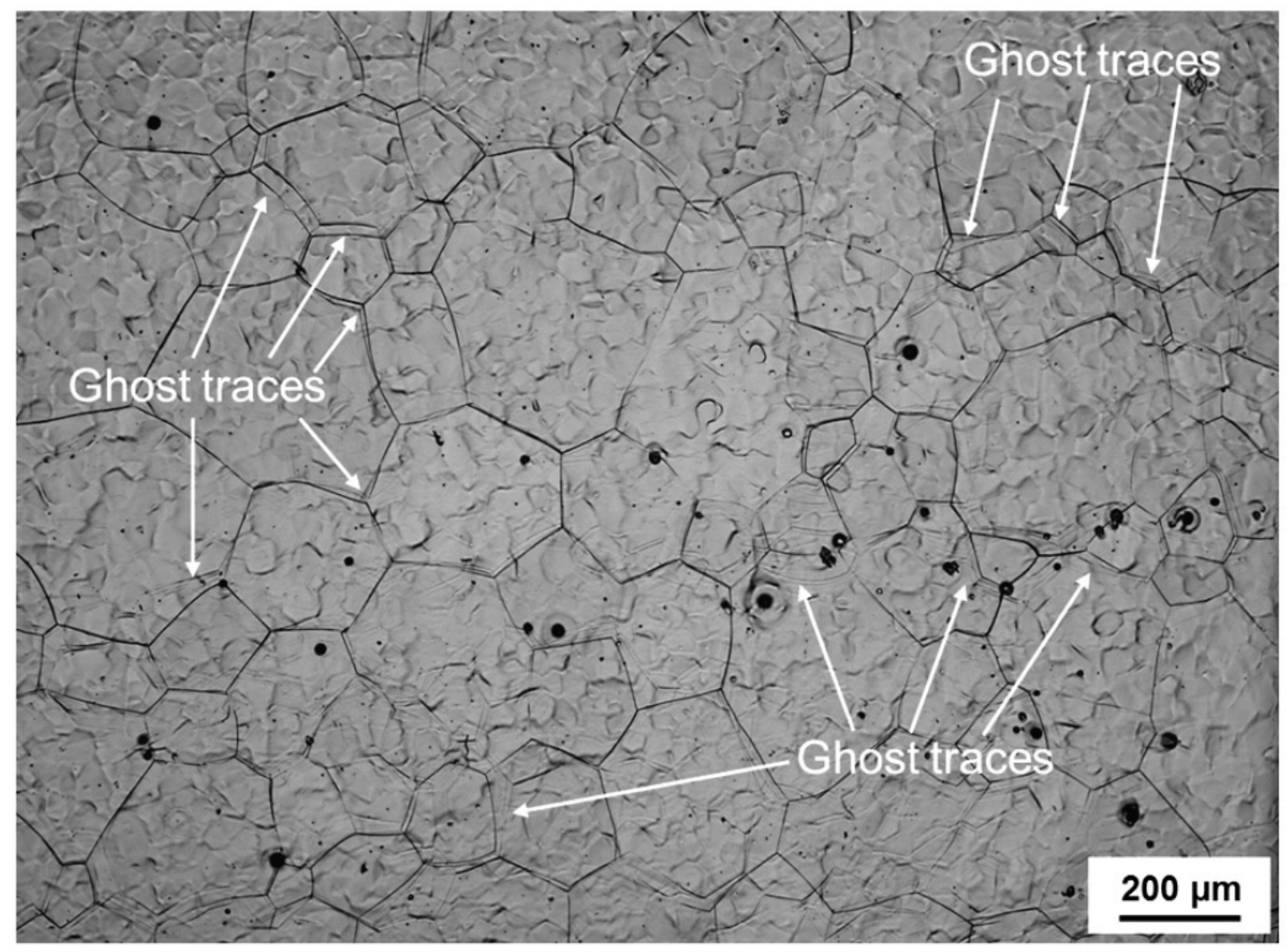

Figure 6 Light optical micrograph showing the prior austenite grain boundaries of the low carbon aluminium alloyed steel under investigation after heating to $1250{ }^{\circ} \mathrm{C}$ for 600 s. Nomarsky microscopy has been employed to highlight grain boundaries. Ghost traces are indicated by arrows. 


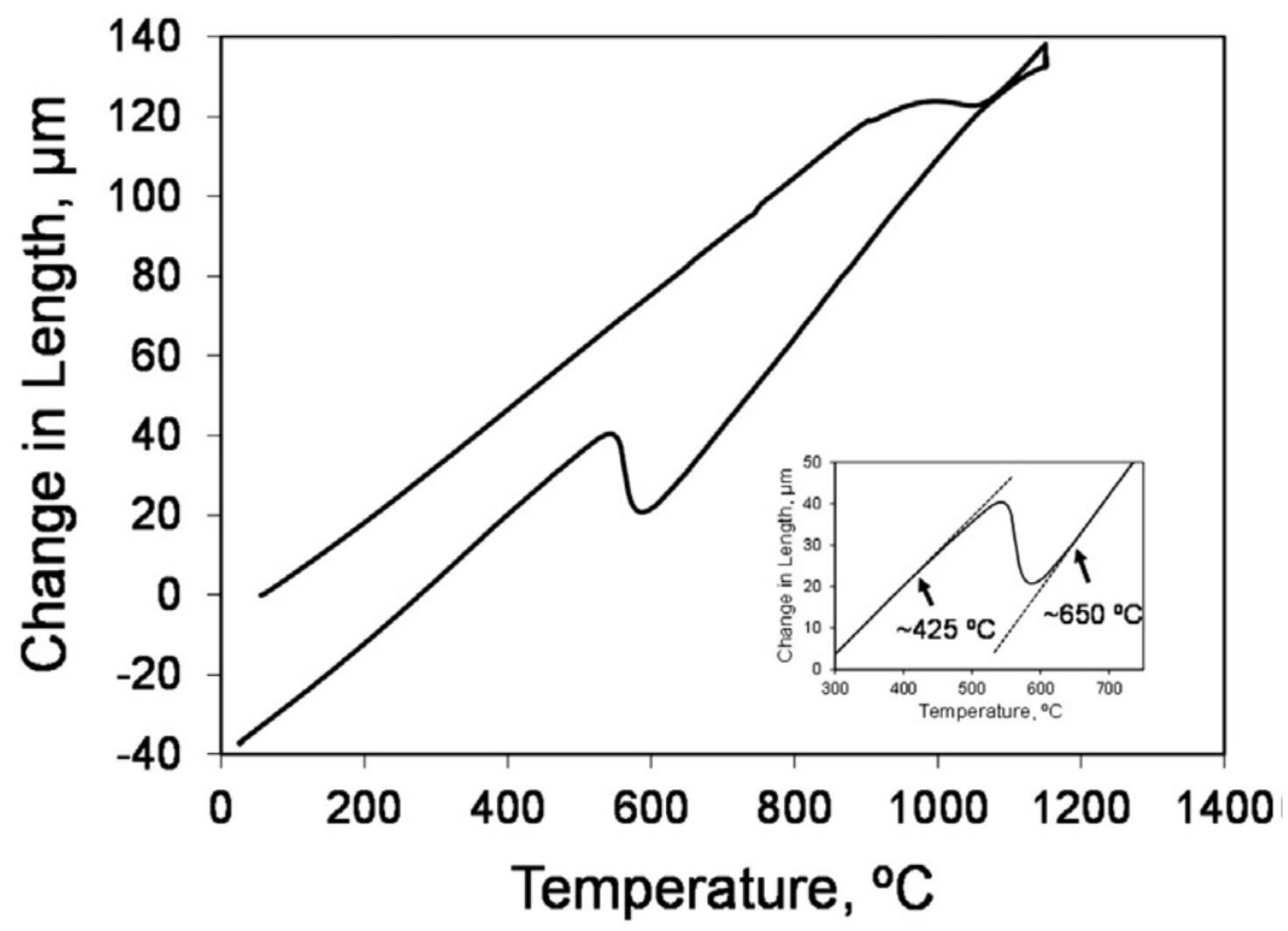

Figure 7 Temperature evolution of the relative change in length. An insert has been included to show the start $\left(650{ }^{\circ} \mathrm{C}\right)$ and end $\left(425^{\circ} \mathrm{C}\right)$ temperatures of the dilatation detected during cooling with more detail. 


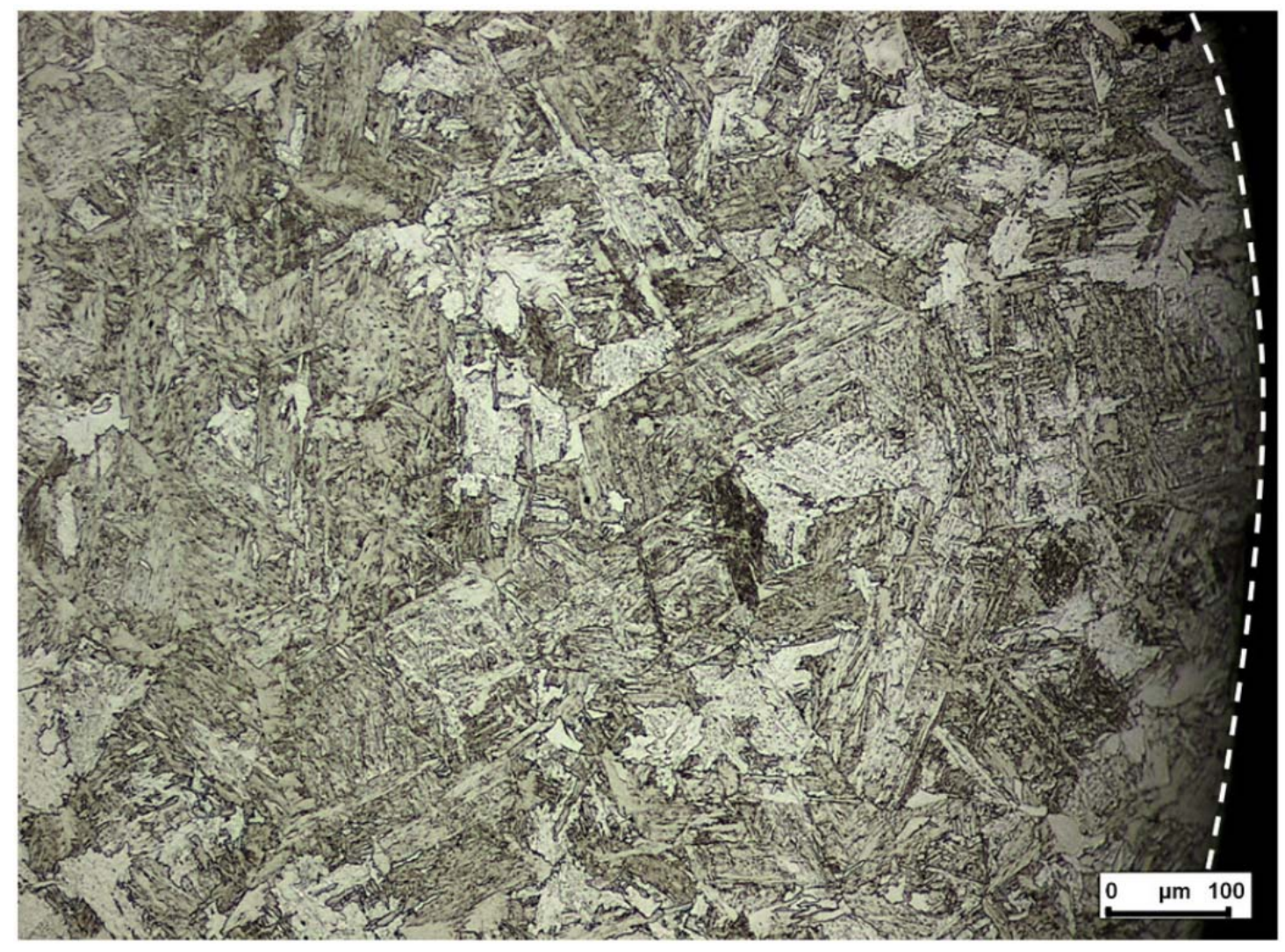

Figure 8 Optical micrograph of the as-quenched microstructure. The border of the sample has been delineated using a white dashed line. 


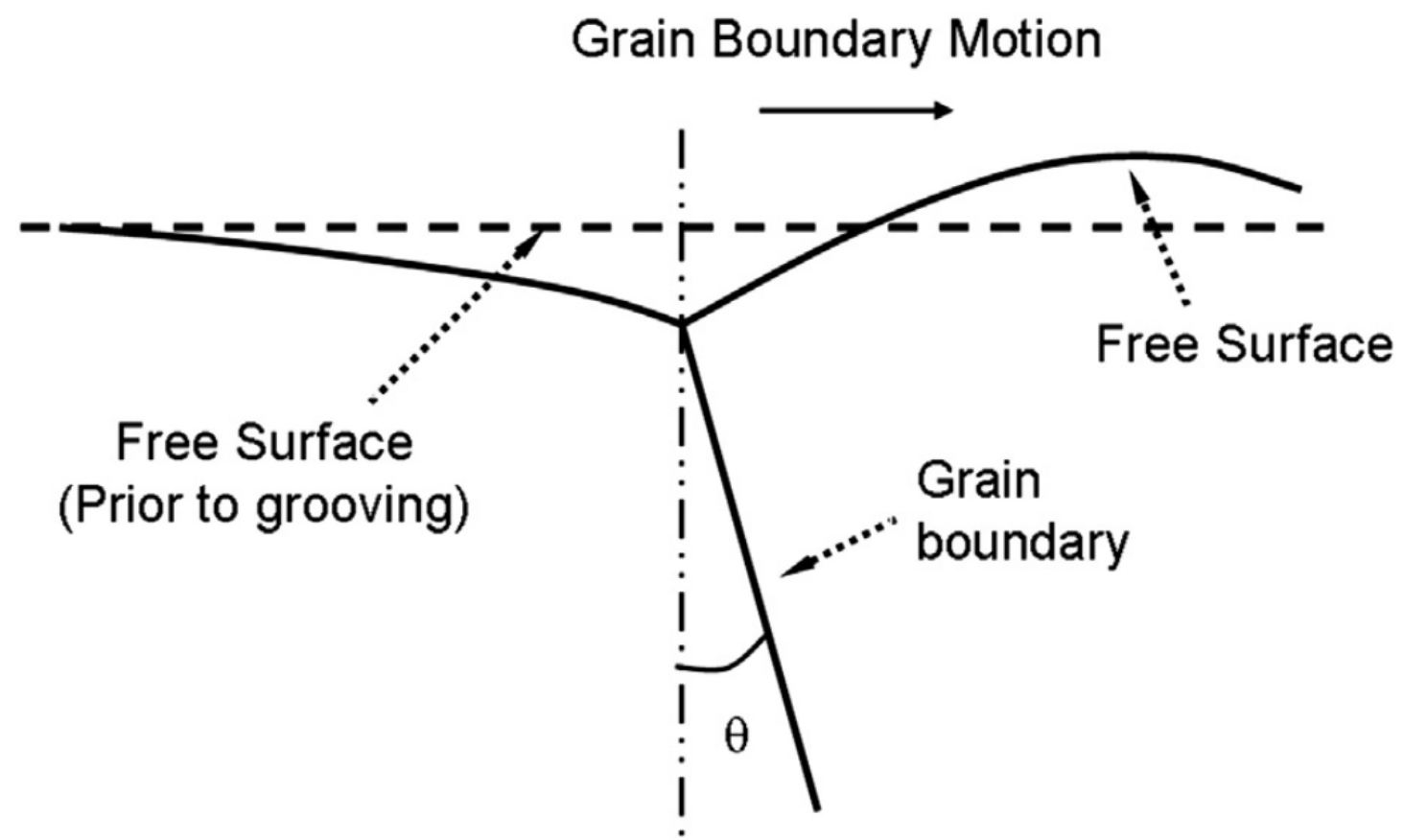

Figure 9 Characteristic steady-state profile of a thermal groove formed at a free surface by a moving grain boundary. Parameter $\theta_{c}$ is the critical grain boundary angle as defined by Mullins [22] (please see text for definition). 
Table 1. Chemical composition (wt.\%) of the steel under investigation (Fe to balance)

\begin{tabular}{ccccccc}
\hline $\mathrm{C}$ & $\mathrm{Si}$ & $\mathrm{Mn}$ & $\mathrm{P}$ & $\mathrm{S}$ & $\mathrm{Al}$ & $\mathrm{N}$ \\
\hline 0.022 & 0.29 & 1.41 & 0.001 & 0.001 & 0.94 & 0.001 \\
\hline
\end{tabular}

